\title{
Innovative Teaching Experiences: Globalization via Collaboration
}

\author{
Tahereh Alavi Hojjat ${ }^{1}$ and Ana- Maria Preda ${ }^{2}$ \\ ${ }^{1}$ DeSales University, USA \\ ${ }^{2}$ Romanian American University, Bucharest Romania
}

\begin{abstract}
It has become increasingly more important with the rapid progress of internationalization to have a broad view based on the awareness that we live in an international society that requires us to achieve mutual understanding beyond our own borders. We are enmeshed in a global web of economic relationships through trading of goods and services, multinational corporations, cooperative ventures among the world's firms, and the ties among the world's financial markets. The global economy affects all of us daily and we cannot ignore the increasing globalization of the world's economies. The education of our students will play an even more important role in globalization in the future. The purpose of this study is to investigate and evaluate how international collaboration in education has helped students in a small University to increase their understanding of the global economy and how exchange of ideas on various economic issues has been playing an increasingly more important key role at the global level. In particular, in this project, the experience of Desales University's collaboration projects will be described to demonstrate the impact of short-term immersion experiences across cultures to develop global competence. Similarly, the role of technology will be discussed to illustrate innovative and cost effective ways to prepare students to become globally competent.
\end{abstract}

Keywords: Education, Globalization, Global Team Working, Economics

\section{Introduction}

Since 1994, the World Wide Web and related Internet resources (e.g. chat, group page, message boards, and emails) have become an increasing viable component in higher education pedagogy. The integration of Web technology into higher education instruction is receiving growing attention within the University community (Flanagan \& Egert, 2000, Bates, 2000). This has led to significant interest in implementation of internet based teaching. In addition, increasing social and economic demands, along with newly developed technologies, have spurred changes in educational delivery systems, student access, and faculty roles. As a result, varieties of model are being developed and implemented ranging from local and global aiming to explore the possibilities of more interactions among students.

Among different features of the Web technology, its potential for supporting collaborative learning processes deserved particular attention among scholars and developers (Anderson \& Kanuka, 1997). Collaborative learning refers to an instructional situation at which students interact while accomplishing an academic task.

There are two learning situations in terms of collaboration: structured and emergent collaborative events. Structured collaborative learning is presented as

Copyright (C) 2011 Tahereh Alavi Hojjat and Ana- Maria Preda. This is an open access article distributed under the Creative Commons Attribution License unported 3.0, which permits unrestricted use, distribution, and reproduction in any medium, provided that original work is properly cited. Contact author: Tahereh Alavi Hojjat e-maill: Tahereh.hojjat@desales.edu 
comprehensive didactic sets, which offers clear definition of the varied aspects of the activity, e.g., goals, contents, distribution of roles or required functions, stages in the process (Nachmias, Mioduser, Ram, 2000). Emergent collaboration is the process by which group configurations and transactional patterns evolve among participants during the course of learning in a specific course (Ibid, p. 95). This planning process will focus on the definition of goals and constraints, rather than on the detailed formulation of structural or organizational aspects.

In this project, we adopted the emergentcollaboration approach, along with all regular duties of the face-to-face course (e.g. lectures, assignment, group meetings), the students participated in additional web-based global activities. The project has been attractive to us because it provides a unique opportunity for American students to exchange opinions and thoughts with international students with different background and experiences.

\section{Web-Supported Global Interactions}

There are several new, and now enduring, realities facing the business world as a result of the powerful force of globalization: countries have permeable boundaries, and in cases where economic integration is occurring those boundaries have disappeared; the workforce is more global today than could ever be imagined even ten years ago; the business playing field is level in most parts of the globe and will soon be the same in other parts; the future workforce is part of a highly technologically driven network in which virtual collaboration is the norm; the notion of a local company is increasingly becoming a thing of the past; and the robust new economies of India, China and other economically integrated regions are demanding new skills and attitudes.

Even higher education is not able to escape the influence of globalization. There is a massive realignment of higher education taking place, one similar to Thomas Friedman's emerging "flat world" of globalized innovation. A new playing field is being created, with new paradigms and rules as a result of Bologna and ERAMUS, WTO open markets for higher education, the rise of reputable institutions abroad, the diffusion of technology (Internet 2 and MIT's \$100 laptop) and technologicallymediated collaboration between U.S. and foreign universities, the outsourcing of basic academic lab research functions, and the increased market penetration of forprofit and distance education options. Like business, higher education is becoming global in both missions and markets.

The landscape described above raises a question about the kind of students that universities in general, and business programs in particular, should be producing. However one defines the product, it seems clear that educational institutions all over the world must produce globally competent graduates.

This research paper will offer new models for developing globally competent graduates. In particular, the experience of Desales University's collaboration projects will be described to demonstrate the impact of short-term immersion experiences across cultures to develop global competence. Similarly, the role of technology will be discussed to illustrate innovative and cost effective ways to prepare students to become globally competent.

DeSales University is a private, 4-year Catholic university with 1,561 full-time traditional undergraduate students (http://www.desales.edu). The total enrollment is 2,499 students in this regional teaching institution that includes graduate and non-traditional undergraduate students. Recently, the university launched a globalization initiative in order to internationalize the curricula and expose students to intercultural elements in their education. As part of this initiative, agreements were signed with institutions in Peru, India, Romania and Germany to provide students and faculty with diverse experiences abroad. The Division of Business and the MBA program added their own goals to the 
university's goals in the globalization initiative.

We want to share how, via collaboration, students can:

1. explore the background factors including culture, religion, physical environment and demography that stand behind and influence the region's political economy;

2. understand economic institutions, policies, and issues that define the region's present and which are relevant to its future and

3. compare and attempt to explain the region's economic development relative to the US and other parts of the world.

Faculties across the country have begun to use travel and technology to incorporate global components into their curricula in order to increase their students' global literacy. We would like to demonstrate that there are other tools that can be effective to reach this goal. Within the past seven years, we have been using the internet, Blackboard and then Angel as a platform to collaborate with professors and students in Romania. The results of this international collaboration have been so positive allowing us to engage another country, Bulgaria, in our team this year, spring 2010.

Global-ready graduates can leave their college or university and move seamlessly into multinational organizational environments, recognize them, and feel self-confident about their ability to succeed.

This collaborative project broadened and enriched the students' learning experience through collaboration with other international institutions. This has been achieved with Blackboard, an online course management system, using both synchronous and asynchronous methods to promote dialogue among the students and faculty. The project was conducted through a web-based, virtual problem-solving environment in which student teams can complete projects and assignments that address contemporary economic issues at both global and national levels.

In this project, students from the Romanian-American University in Bucharest and DeSales University in Center Valley collaborated. Throughout the semester, students used the group page effectively to engage in teamwork and divide the tasks among each other. Exchange of ideas, opinions and belief about key issues were among the core of group-based knowledge-building processes. Every week, team activities were checked and a group email was sent to all students to encourage them to stay active or become more active. Announcements were made in class and posted on Blackboard on which team was the most active and collaborative one. This team's activity was also demonstrated in Economics class as a best example.

Furthermore, students from both institutions were posting national and international news and business information on the general discussion board to be viewed by all students to learn more about the state of the economy in the US and Romania. A major benefit of this collaborative Project was that, via the discussion board, all students improved their general knowledge, as:

- they found out very actual and accurate Economic news/data (some of them not available in English!) regarding another country;

- they had enough information to do comparisons between countries (though this point could be improved in the future) and they made very interesting and valuable comments (what is right/wrong, why, proposed solutions etc.);

- they met not only new people, but also new customs and traditions, e.g. Dragobete versus Valentine's Day and 1st of March (Martisor), or Easter.

As information is power, multicultural knowledge, and the latest economic news and data is also power. This is why many 
students have appreciated the value of the information posted on the Discussion Board.

Based on the degree of collaboration and quality of teamwork, the five best teams received a Certificate of Achievement. Taking into account the effort that was spent by Romanian students during this collaboration process, we decided to extend our appreciation to most active Romanian students beyond the winning teams to recognize their effort in terms of technical support, posting and exchanging information, taking all examinations and friendly collaboration.

It should be mentioned that some students gave up after the first two collaborating assignments. This occurred after the first month of class because either they could not adjust to the rhythm, or they were "disappointed" by the first "fails in the collaboration" (not answering or not taking into account their opinions etc.). In faculty's opinions, these students have learned a good lesson out of this Project. They have to reconsider their behavior and education in the future, in order to be compatible with their future profession (i.e., "manager", which requires capacity to adapt to different situations/persons, strength to fight and willpower). The students who participated to the end of this Project (and this class) have proved their strength, their tenacity, their wish to complete - with good results - a challenging task, as well as their flexibility and adaptability to various conditions and people. That is why the Project was more than a simple experiment of collaboration; it was a very serious test of personality (resistance, adaptability, communication etc.) for each of the participants. Students collaborate on accomplishing the goals and objectives set up in advance. While working on these ventures, students acquire a wealth of knowledge about the topic as well as gain many additional benefits; applying the concepts and suing the technology without having to focus on managing the projects.

We distributed evaluation forms to the DeSales University students and Romanian students to receive some feedback on the usefulness of collaboration. From these evaluations, we recognized that $40 \%$ of American students and 53\% of Romanian students agreed that this project helped them to understand their colleagues' culture better. Furthermore, $31 \%$ of American and $37 \%$ of Romanian students responded that this project improved their teamwork skills. Also, students were asked to send their testimonial on collaboration, $30 \%$ of the students who responded were very positive as they believed that they acquired a wealth of knowledge by focusing on assigned projects and the point that their work reached a real person, and did not stop in a cold box of a simple online course, gave purpose to the whole experience. Meeting other students through virtual environment was a quite unique experience for the students as they not only learned about their personal and academic life but learned about culture they came from. By exchanging file and even pictures they got a physical representation that was a worthwhile effort.

Students thought collaboration was the beginning of an ongoing stream of openness, acceptance and growth where national boundaries become obsolete and people get excited about sharing ideas scattered in different parts of the globe. Such interaction has planted the kernel of further collaboration which has laid the foundation of a cross-cultural network, which has the potential to grow both in size and in power.

\section{Students' View Points: Bridge to Global Learning}

"The collaboration with Romanian students at Romanian American University in Microeconomics class was truly rewarding". Through the use of technology, students on two separate continents were able to work together throughout the semester on various projects including a main research project. The learning between the students was not limited to economics but was open to all areas of interest especially regarding one another's cultures. As a DeSales student, "I was able to learn about another culture and their 
vibrant and interesting traditions. Although the Romanian students are used to their everyday life, I found their culture and country to be fascinating and unique. They have very distinct customs and many special holidays. It appears as though their holidays, even the small ones, are very important to them and are celebrated by a vast majority. The pictures of their country were beautiful and would make anyone want to visit there. I found their strong work ethic, drive for learning, and their unique holidays to be the most distinct cultural differences". As for the technology that we utilized, the main technology was Blackboard. Each group also utilized email and instant messenger. Blackboard made the initial connections easy. Also, with the significant time differences of six hours between our two countries, it was easy to leave one another messages through Blackboard when it was convenient for each of us.

Team building skills and time management skills played a big part of this project. It was very beneficial to have the small collaborating assignments during the beginning of the semester to get the students used to working together. It also helped the students to realize how long it would take to get an assignment done with the time differences, this task prepared us for our main project. Also, the professor continued to keep us on track by having various parts of the project due throughout the semester. This was very helpful for time management purposes. "I felt that the three most important benefits overall were centered around globalization. First, I felt the interaction with another student across the world really helped connect the DeSales students to the rest of the world. It helped us to broaden our horizons and learn about another culture. Second, I think it instilled, in many of the students, an interest to learn about and visit other cultures. Third, it also allowed us to make friends with a student who we could share our culture with and learn about their culture all the while realizing the many differences but also the many similarities. Although it's cliché, it truly is a small world after all. All in all, I felt the collaborative class was extremely beneficial. Although it may have been tough at times to work on a project with students across the globe, it was highly rewarding and totally worth it in the end. I would definitely be interested in taking another collaborative class".

The following are some additional students' feedback from collaboration:

"I learned so much about Romanian culture, their holiday, their education system, and about their university. I thoroughly enjoyed working with Nicolae, a Romanian student, I found him to be extremely helpful, gifted and efficient student and partner. I consider him an overseas friend whom I look forward to meeting when he comes to US". Another student wrote "Beyond obvious benefits of the team work experience, I believe this collaboration had delivered a great deal more. Personally and professionally, I believe that people must look outside the borders of their country, and notice and learn what is best from the various cultures they come in contact with. I believe that progress is possible only if one is willing and able to accept and appreciate crosscultural thought systems and techniques of action. And once again, I believe that what we have accomplished was the first step in an ongoing stream of openness, acceptance and growth. The collaboration has illustrated and confirmed the phenomenon of modern project management, according to which: as national boundaries become obsolete and as people who get excited about an idea scattered in a different parts of the globe can intellectually reach each other in real time; motivation and expertise take the place of convenient spatial proximity as the forces that unite the members of the team. As such, this phenomenon results in pure efficiency". Another student wrote: "I believe that our collaboration has planted the kernel of future collaboration and that it has laid the foundation of a cross-cultural network which has the potential to grow both in size and in power". Another Romanian student said: "working on a collaborative project was interesting and motivating; I guess the fact that your opinions and work actually reached a real person, and did not stop in a cold inbox of a simple online course, gave 
purpose to the whole experience. Also, having a partner interested in the collaboration that gets involved and brings his/her contribution to the final outcome definitely makes the difference. After the work is done, it's nice that you "met" new people, found about their personal and academic life and learned new things about the culture they come from. When I attach some pictures in "file exchange" folder and the other person gets a physical representation, so to speak you know it's worth the effort". Another student said" The collaboration with American students is without doubt a solid example which can confirm the benefits of a modern and efficient internet communication. Moreover, this is a revolutionary method of learning and studying, entirely based on team spirit, communication, seriousness or the ability of coping with other teaching styles". "Through collaboration, I had an opportunity to meet new people with another way of thinking and the chance to improve my knowledge not only economics but also English, I must recognize that it indeed was a great experience".

Ashley Eisenhart '11 and Aaron Gildner '11, both are double major in Accounting and Finance and they were recently recognized for publication of their paper in the spring 2010 edition of the Neumann Business Review-an academic journal that focuses on business topics on both a national and global scale. Their paper, "The Status of the Airline Industries in the United States and Romania" was written as a research paper and assignment for the Microeconomics course. "Along with our Romanian partners, we worked extremely hard on this research paper," said Eisenhart. "It's a great feeling to know our efforts were recognized on a professional level." The most rewarding part for Eisenhart was the opportunity to interact with students across the globe. The students wrote their award-winning paper while struggling against the challenges of international communication-a valuable experience for everyone involved.

"This has been a great experience and we are thankful that we had this opportunity," said Eisenhart. Gildner added that they are "truly grateful to receive such an honor as a result of our hard work. While we knew that we had compiled a quality researchpaper analyzing the airline industries of the United States and Romania, it is still unbelievable that academics may use this publication in support of future research papers." Gildner agreed with Eisenhart that the most satisfying part of this entire process was collaborating with the RAU students. "While differences in time zones, language barriers, and a lack of direct contact with half of our group members may have provided potential difficulties, we overcame these obstacles to achieve a quality result as well as a practical exposure to communication skills on a global scale," he said. International collaboration is an important aspect of business. Communicating with others across the world as undergraduates is a valuable experience and opportunity that will benefit them in their future careers and lives

(http://desales.edu/assets/desales/Busine ss/busnwsltrFa10.pdf)

The Project also strengthened the professional and personal links (relations) among teachers (faculty members) from different countries and institutions. We have known each other better, we have learned a lot by working together (though being, geographically, so far!), we have exchanged ideas, and we have improved ourselves.

\section{Lessons Learned}

Although the overall experiences for both undergraduate and graduate courses were positive, the faculty and students learned several lessons to improve the collaborative experience in the future. For the faculty, preparation and planning are critical elements in ensuring a successful learning experience. Course materials, especially the syllabus and assignments, need to have clear expectations and wellstructured parameters. Because so much of the class interaction is online, course documents need to be designed and 
developed for the online interface and environment. Setting expectations and deadlines is paramount because of the issues related to time zones, cultural differences, work ethic and language.

Communication between faculty and students and among students in a crosscultural joint project is the glue that helps bind all other elements together. We also learned to provide smaller and less critical assignment modules/units so that trust and protocols can be built between teams before embarking on a large, end-of-thesemester collaborative initiative. In the graduate course, for example, 1-2 American and 2-3 Romanian students worked in small groups to submit 4 assignments before starting on their main application project .We think that the idea of collaboration was an excellent way to learn and enhance DeSales University's global readiness and improve students' teamwork experience. Global collaboration allowed our students to learn that multiple versions of ideas, content, experiences and perspectives do exist, and can be mutually beneficial and sustainable. For faculty, it was a challenging but ultimately rewarding experience to experience cross-cultural collaboration and build bridges with another country's students. We also explored multiple venues of future research collaboration with Romanian faculty. These innovative experiences have allowed us to design, develop, implement and sustain a truly global learning community without regional, geographical, linguistic or cultural boundaries.

\section{Summary}

We think that the idea of collaboration was an excellent way to learn and enhance our global readiness and improve students' teamwork experience. We are grateful to share our ideas with other colleagues to improve our students' teamwork skill and their global readiness. Our students felt the same way. They not only gained important skills such as team work, time management, and global knowledge about other countries, but they also made new friends. Global collaboration allowed our students to learn that multiple versions of ideas, content, experiences and perspectives do exist, and can be mutually beneficial and sustainable. At the end, they realized that there are more similarities than differences.

Overall, students learned that the collaboration process was a great learning experience and very useful tool to allow them to enhance their team work, time management and to resolve their conflict, if any and improve their cultural literacy. The most exciting thing about collaboration was that we had to do projects together without knowing each other. The team projects are a good opportunity to help improve and build relations with other countries. We observed that participating on the project helped students improve English language skills as well as exchange ideas and opinions about another's culture, politics, religion, music and art.

They learned about different life style as a college student, direct communication through group page build in Blackboard/Angel helped students to cut through some of the stereotypes and misperceptions that many cultures have of one another.

The Project proved that collaboration via Blackboard/Angel was not only a very interesting and useful experiment, but also a challenging "pedagogical" experience. We had to "invent" (develop, create) and use (put into practice, experiment) different pedagogical strategies for different stages of the Project, in order to intensify, to stimulate, and to encourage the students' collaboration. This was conducted through sending messages to the students on best performers in their collaborative projects on both sides. Furthermore, the group page was reviewed for further evaluation to measure the intensity of their interaction and make comments to encourage them for continuation of meaningful collaboration.

In order to prepare students for collaboration, different steps were taken. First, we created three collaborative assignments, just to "train" students to collaborate via Blackboard. Second, the three collaborative assignments have been 
constructed gradually (the first was "a personal knowledge of each other", the second was "a knowledge about the economic environment of each other", and the third was a first collaborating experiment on a given topic (Supply and Demand)). Third, we have encouraged the students' collaboration by using "bonus points techniques" which required a reciprocal knowledge to allow them to appreciate learning not only about the business projects and economic environment of the other country(s) but also to adapt to a different culture. In our opinion, these could be considered "pedagogical innovations" (or at least "pedagogical reactions") developed in order to adapt to certain situations! In short:

The Project enhanced the capacity of each student to adapt to:

- different cultures

- different working hours (6 hours in advance for Romania!)

- different characters (personalities)

- different educational systems, with different theoretical and practical approaches.

The Collaborative Project was challenging for all participants, both students and teachers. I think that it was more than a simple professional experiment for the Economics class; it was, at the same time, a sociological and pedagogical experiment. Also, the Romanian participation to this Project was, both for the students, and the teachers, an excellent means of practicing and improving our communication in English".

We hope that this collaborative project will continue and develop, taking into account the exceptional power of the technology available for collaboration over the internet. Also, we think that the experience we gained together is valuable and worthy of sharing among our colleagues and other academic institutions.

\section{References}

Anderson, T. \& Kanuka, H. (1997). "Online Forums: New Platforms for Professional Development and Group Collaboration," Journal of Computer Mediated Communication, 3 (3).

http://jcmc.huji.ac.i1/vol3/issue3/anderso n.html

Bates, A. (2000). Managing Technological Change, San Francisco: Jossey-Bass.

Flanagan, M., \& Egert, C. (2000)."Courseware Quality and the Collaborative Classroom: Implementing IOS Courseware to Generate Seminar-Style Interactions," IMEj, 2 (1) http://imej.wfu.edu/articles/2000/1/inde x.asp

Nachmia, R., Mioduser, D., Oren, A. \& Ram, J. (2000), "Web-Supported EmergentCollaboration In Higher Education Course," Educational Technology \& Society 3 (3), 2000.

Rhoads, J. (2010). "Students Awarded for publishing Joint Research Paper", Business Matters P.5

http://desales.edu/assets/desales/Busines s/busnwsltrFa10.pdf 